\title{
Análisis de algunos hitos históricos de los Derechos Humanos en Occidente
}

\section{Historical landmark analysis of western human rights}

Fundación Universitaria Católica Lumen Gentium, Cali, Valle del Cauca-Colombia. Correo electrónico: direccionposgrados@unicatolica. edu.co

\section{Resumen}

Dayana Alexandra Hurtado Reyes

En este artículo están consignados algunos hitos históricos que permitieron explorar varios elementos genealógicos relacionados con los derechos humanos. Estos derechos representan una de las mayores conquistas de la humanidad, los cuales tienen su ápice en las declaraciones de la segunda mitad del siglo XX. En la búsqueda de esos principales hitos históricos de los Derechos Humanos en occidente, se revisó, en primer lugar, el periodo denominado primera modernidad, (siglos XVI y XVIII); en segundo lugar, el surgimiento de la Declaración del 10 de diciembre de 1948 y su repercusión en la época de la posguerra. Para este análisis, se trabajó con el método hermenéutico, pues se trataba de interpretar un fenómeno: los Derechos Humanos a través de algunos hitos históricos, a partir de un campo específico: la filosofía.

Palabras clave: derechos humanos, dignidad humana, persona, modernidad, ética.

\section{Abstract}

In this article, was consigned some historical milestones that allow to explore several genealogical elements related with human rights. These rights represent one of the greatest achievements of humankind, which have their apex in the statements of the second half of the twentieth century. In the search of those main historical milestones of the Human Rights in west, revised first, the period called first modernity, (sixteenth and eighteenth centuries); second, the emergence of the statements of December 10th of 1948 and its repercussion in the post-war era. For this analysis, we worked with the hermeneutical method, as it was trying to interpret a phenom- 
enon: the Human Rights through some historical milestones, from a specific field: the philosophy.

Keywords: Human rights, human dignity, person, modernity, ethics.

\section{Introducción}

Enseguida, se presentan algunas ideas generales sobre varios de los hitos de los derechos humanos (DDHH); sobre todo, en la modernidad. El propósito es volver sobre esos hitos históricos para revisar los elementos genealógicos relacionados con los DDHH, una de las mayores conquistas de la humanidad. En este interesante análisis, no se puede pasar por alto la idea de dignidad humana. Ella está en el centro mismo de los DDHH, ya que estos no existen en sí y por sí. En efecto, son referentes aplicados a "alguien", al hombre mismo, dotado del valor más propio y sublime que lo identifica: su dignidad. Dicho de otra manera: la conquista de los DDHH no es otra cosa que la lucha por la dignidad humana. En este sentido, los DDHH representan una teoría ética contemporánea, conformada por principios, valores, criterios y normas, que orientan el comportamiento humano tanto personal como social.

Como bien se sabe, la historia de los derechos humanos es producto de los principales acontecimientos del siglo XX, causados por las dos guerras mundiales, los cuales dieron origen a la lucha por: la dignidad humana, las libertades individuales, la igualdad social y el reconocimiento de toda la"especie humana". Y todo, por el solo hecho de hacer parte de ella, sin distingos de grupo étnico, nacionalidad, ideología, religión, etc. Sin embargo, los derechos humanos se reconocieron oficial y universalmente, solo cuando se establecieron las Naciones Unidas. La convulsión y las atrocidades de la Segunda Guerra Mundial (de ahora en adelante SGM) y la incipiente lucha de las naciones coloniales por la independencia alentaron a los países del mundo a crear un foro para hacer frente a algunas de las consecuencias de la guerra. En particular, para evitar que se repitieran los terribles sucesos vividos. Ese foro fue la organización internacional, denominada Naciones Unidas.

Desde su fundación, en 1945, las Naciones Unidas reafirmaron su fe en los derechos humanos de todos los pueblos que las integran. En su Carta fundacional, está establecido que los derechos humanos son el centro de sus preocupaciones; así, han seguido desde entonces.

Uno de los principales logros de las Naciones Unidas, poco después de su fundación, fue la Declaración Universal de Derechos Humanos (DUDH), aprobada por la Asamblea General de las Naciones Unidas el 10 de diciembre de 1948. Este valioso instrumento sigue ejerciendo una influencia considerable en las vidas de las personas de todo el mundo. Por primera vez en la historia, un documento considerado de valor universal era aprobado por una organización internacional. También, por primera vez, se enunciaban detalladamente los derechos humanos y las libertades fundamentales.

En la Declaración, se considera que "la libertad, la justicia y la paz en el mundo tienen por base el reconocimiento de la dignidad intrínseca... de todos los miembros de la familia humana" y que esa dignidad está vinculada al reconocimiento de los derechos fundamentales, a los que todo ser humano aspira. Los cuales son:

- el derecho a la vida, a la libertad y a la seguridad de las personas;

- el derecho a un nivel de vida adecuado;

- el derecho a buscar asilo y a disfrutar de él en cualquier país en caso de persecución;

- el derecho a la propiedad;

- el derecho a la libertad de opinión y expresión;

- el derecho a la libertad de pensamiento, conciencia y religión;

- y el derecho a no ser torturado ni sometido a tratos, o penas, crueles, inhumanos o degradantes.

Estos derechos son intrínsecos y deben disfrutarlos todos los habitantes de la aldea mundial (mujeres, hombres, niños y todos los grupos de la sociedad; desfavorecidos o no). De ninguna manera, son "concesiones" que puedan retirarse, negarse o cambiarse.

Es pertinente dejar claro que los más de 55 millones de víctimas, resultado de los conflictos efectuados durante la SGM (1939-1945), marcaron un momento decisivo en la conformación de los derechos fundamentales, las libertades, la igualdad y la dignidad del ser humano en las democracias occidentales. Sobre todo, marcó un momento en la determina- 
ción del ser humano, como sujeto de derechos y obligaciones. Por tanto, el derecho a la vida, a la libertad, al desarrollo libre de la personalidad, a la educación, al trabajo, a la salud, a la vivienda; en fin, a una vida digna, son el centro de la persona. Por consiguiente, representan un tema central en las agendas gubernamentales y no gubernamentales de los estados modernos.

\section{Historia de los derechos humanos}

\section{Los derechos humanos en la Primera Modernidad $^{1}$}

Pese a todo lo anterior, distintos autores, entre ellos Angello Papachini, consideran que, en sentido estricto, el origen de los DDHH se inicia durante el periodo de transición entre el Medioevo y la primera modernidad, periodo conocido como Renacimiento, pues se centró la atención en el $\mathrm{Hu}$ manismo.

[...] En su configuración específica (los DDHH) son un producto de la modernidad. Su consolidación resultaría impensable por fuera de algunos fenómenos concomitantes que definen la modernidad en el plano ético-político: separación de niveles entre moral, derecho y religión; consolidación de un Estado no confesional y laico; derrumbe del ordenamiento social feudal por estamentos y surgimiento de una individualidad libre. (Papachini, 1998, p. 2).

\footnotetext{
1 El discurso de la modernidad es, quizá; uno de los más analizados y llamativos de la actualidad, ya sea para afianzarlo como discurso o para contradecirlo. Todos, desde nuestras propias posturas y convicciones, afirmamos ser más o menos modernos. De hecho, Sócrates, Agustín de Hipona o Thoureau fueron modernos. El historiador y epistemólogo estadunidense, Andrés Koyré, afirma en su obra: "El pensamiento moderno": ¿El término modernidad tiene en general algún sentido? Siempre se es moderno, en toda época, desde el momento en que uno piensa más o menos como sus contemporáneos y de forma un poco distinta que sus maestros... Nos Moderni, decía Roger Bacon [...] ¿No es en general vano querer establecer en la continuidad del devenir histórico una división cualesquiera? La discontinuidad que con ellas se introduce, ¿no es artificial y falsa?

Ulrich Beck se refiere a la primera modernidad como el periodo en el que aún existen fronteras y demarcaciones claras entre sociedad y naturaleza, individualidad y colectividad, entre guerra y paz, entre el yo y los otros; incluso las fronteras de los Estados-nación, con sus propias decisiones políticas. Cobija los periodos desde el siglo XVI hasta el siglo XVIII. A partir de la Segunda Guerra Mundial, se habla de la segunda modernidad, como el periodo en el que desaparecieron las fronteras, y se creó una nueva conciencia social, con otras características, con otros sentidos y con otros discursos.
}

Este mismo autor considera que, fundamentalmente, son tres los elementos esenciales que influyen durante este período, para la configuración moderna de los DDHH: a) el giro del teocentrismo al antropocentrismo; b) el surgimiento del individualismo con características sociales; y c) la centralidad de la razón y la irreverencia a lo divino y a la tradición.

El encuentro de dos mundos resultó un arma de doble filo que, si bien, por un lado, trató de unificar un pensamiento más universalista sobre el hombre; por otro, desató la codicia de encontrar poder y fortuna por encima de los pueblos conquistados, su cultura y sus costumbres. En efecto, con el inicio de los primeros estados imperialistas y su conquista de nuevas tierras, el criterio de derechos humanos pasó a reglamentarse, según las conveniencias de las naciones conquistadoras. Fue cuando los imperios europeos sometieron y esclavizaron, de distintas maneras, a poblaciones enteras de los continentes americano y africano, durante los siglos XV, XVI y XVII, con el fin de completar la demanda de esclavos: la"moral" griega en su máximo apogeo.

En este sentido, los conflictos sociales de carácter religioso -acontecidos en las potencias europeas (sobre todo, inglesas, francesas, españolas y holandesas) de los siglos XVI y XVII, y en las ideas del puritanismo británico- configuran el Sitz im Leben moderno del surgimiento de los DDHH. Estas ideas lograron gran influencia en la sociedad de su tiempo; se distinguen las del teólogo suizo John Calvino (1509-1564) y el filósofo inglés John Locke (1632-1704).

Salir del estado de naturaleza -en el que el hombre posee derechos naturales que no le pertenecen como creaciones suyas, sino que dimanan de la voluntad divina (en el que no se considera sujeto al "derecho positivo" del Estado y a ninguna autoridad humana)- implica renunciar a buena parte de los derechos naturales, para someterse al derecho común del Gobierno. En palabras de Bobbio (1996), implica, para los filósofos iusnaturalistas, la existencia de un pacto o contrato social, mediante el cual el individuo cede parte de sus derechos al Estado, y este, como contraprestación, debe proteger sus "derechos humanos" y dedicarse exclusivamente a esa tarea.

Dicho en los términos del filósofo inglés David Hume (1711-1776): la intención manifiesta de identificar lo 
"bueno" con lo "natural" se denomina -en filosofíafalacia naturalista; es decir que algo es bueno porque es natural. La mayoría de teorías éticas ha incurrido en este tipo de falacia, que consiste en justificar la bondad de algo por el solo hecho de considerarlo "natural". Sin embargo, los conceptos de lo que puede ser o dejar de ser"natural" son muy heterogéneos y van desde lo relacionado con la misma naturaleza hasta el concepto de Dios. En definitiva, se trata de identificar, con lo "natural", lo que cada uno considera bueno y así justificar su prevalencia sobre otros conceptos. Esto ocurre con los derechos humanos, cuyo fundamento es la"ley natural" que, por el hecho mismo de ser natural, es emanación de la voluntad divina y, por consiguiente, es a todas luces buena.

El Estado es una consecuencia natural, surge de un impulso social implantado por Dios en el hombre [...] La formación del Estado, con el consiguiente nombramiento de gobernantes para la promoción de los intereses comunes y el bienestar del grupo y la administración de la justicia, es también una disposición providencial de Dios con respecto al hombre. (Meeter, p.105).

Según el estudioso Boron (2000), a John Locke (1632-1704), se le atribuye haber sido el padre espiritual de los "derechos humanos"; por obvias razones: estos derechos estaban trazados con su filosofía individualista, egoísta, basada en el lucro y dependientes de la "ley natural", bajo la doctrina de la "Soberanía Absoluta de Dios". Consecuente con sus postulados naturalistas, el principal derecho -entre los derechos humanos de Locke- es el de la propiedad privada, el cual constituye la plataforma fundamental para otorgar los demás derechos personales como libertad personal, libertad religiosa, derecho a elegir; entre otros.

El ensayo, sobre el Gobierno Civil de Locke, representa la primera teorización del liberalismo político moderno y ejerció gran influencia en el siglo XVIII. Locke se opuso a Sir Robert Filmer (1588-1653), al negar el derecho divino de los reyes; y describe la condición humana sin gobierno alguno, es decir, en "estado de naturaleza". Según este postulado -para proteger la vida, la libertad y la propiedad- los hombres cambian "el estado de naturaleza" por el "estado de sociedad"; en otras palabras, aceptan el fallo de un juez, en asuntos de conducta.
Después, esta teoría (la de los postulados de Locke) fue muy criticada por Hegel (1770-1831), filósofo alemán idealista y por las teorías materialistas y económicas del filósofo Marx (1818-1883). Estas se referían, sobre todo, al "estado de naturaleza". Por esa naturaleza humana a la cual se alude, muchos han confundido las denominaciones sobre igualdad; lo cual las llevó a sus propios intereses y a sus propios juicios sobre la humanidad y sus igualdades.

En la consolidación de los DDHH, durante la llamada primera modernidad, surgen las Declaraciones abstractas, con un contenido político. Que se produjeron después de los periodos revolucionarios, los que introdujeron, a su vez, grandes cambios sociales, políticos y jurídicos en algunos países europeos y en Norteamérica, hacia finales del siglo XVIII. Estos cambios, en la estructura social, estuvieron asociados a la consolidación del Estado de derecho liberal, que fue consecuente con la instauración de los derechos liberales, mediante la limitación del poder del Estado, y de las diferentes instituciones que se crearon con la sociedad moderna democrática.

Entonces, la universalidad de los derechos, además de ser una aspiración humana con un contenido especialmente filosófico, buscó darle un contenido a la función de los diversos sistemas sociales para que estos tuviesen en cuenta, desde estos cimientos filosóficos, los Derechos del Hombre y del Ciudadano, como se les llamó en primera instancia. También, para que éstos contribuyeran a su realización (Peces, 1994). Según Moreno (2010). Después de la Revolución Francesa, vino la declaración de los derechos del hombre. Este documento fue aprobado por la Asamblea Nacional de Francia, el 5 de mayo de 1789. En él, se fijaron los principios en los que debían descansar la sociedad civil y el Gobierno. De hecho, se convirtió en el derrotero de muchas de las cartas magnas y actas de independencia en Occidente. Esta declaración proclama las libertades inalienables del individuo, garantiza los derechos de la libertad, propiedad y seguridad; la libertad de palabra, prensa y reunión; establece que la ley es la voluntad del pueblo y, por ende, es aplicable a todos, sin distingo de clases.

En suma, los fundamentos universales y abstractos predicados por la filosofía ilustrada humanista, que dieron origen a la Declaración Universal de los Derechos Humanos, fueron: los valores, la moral, la 
dignidad, la libertad, la persona, la racionalidad y la cultura del respeto hacia estos derechos (Massini, 2004).

Los Derechos del Hombre y del Ciudadano fueron proclamados en Francia, después de la toma de la Bastilla.Y se difundieron en Occidente, gracias a las revoluciones liberales. Estos derechos han tenido una larga tradición entre las naciones latinoamericanas, en particular, en las antiguas colonias españolas en América. En el caso del actual territorio colombiano, los 17 artículos de los Derechos del Hombre y del Ciudadano fueron traducidos por Antonio Nariño, en 1793. A la postre, una vez realizada nuestra independencia política de la Corona Española, fundamentaron las siete constituciones políticas, proclamadas a lo largo de la historia de Colombia. La Revolución Francesa tuvo -como acto importante, para el caso que se trata en este escritola unidad de pensamiento sobre los Derechos del Hombre, en un contexto ya político y constitucional.

Voltaire, Rousseau, Montesquieu, durante el llamado Siglo de las Luces, realizan grandes aportes a los DDHH. Hay que destacar el Tratado sobre la Tolerancia (1763) de Voltaire, publicado casi un siglo después de la obra de Locke. A pesar de que no le hace justicia al cristianismo y a la Edad Media, Voltaire admiró el sistema político inglés, porque no admitía formas permanentes en las instituciones: argumentaba que no había una ley fundamental, excepto la que asegura la libertad al pueblo.

Voltaire (1698-1762) analiza el caso de Juan Calas², con el cual rastrea la intolerancia como la forma más dañina de humanidad, puesto que rebaja y mina la dignidad humana a un estado mínimo; incluso, por debajo de los animales. "El derecho de intolerancia es absurdo y bárbaro; es el derecho de los tigres, e incluso más horrible, puesto que los tigres no se destrozan sino para comer, y nosotros nos hemos exterminado por unas frases" (1976, p. 42-43). La tolerancia, pues, constituye un imperativo fundamental para construir unas bases bien fundadas sobre los DDHH, tan universales y legítimas como el no hacer a otro lo que no queremos que nos hagan. En los siglos XVII y XVIII,

\footnotetext{
$2 \quad$ Un modesto comerciante de Toulouse, enjuiciado por el Parlamente de su ciudad porque se pensó que había asesinado a uno de sus hijos, por querer convertirse al catolicismo, y por sus creencias protestantes. Voltaire narra este hecho en su Tratado sobre la tolerancia y lo coloca como símbolo de la intolerancia religiosa del momento.
}

de la intolerancia religiosa -presente en casi todas las religiones- se pasó a la intolerancia ideológica, política, racial, cultural y a otras más.

Según Ramírez (2010), lo inalienable para el hombre es el derecho a ejercer su libertad desde su lógica y razón como ser humano. Como se dijo anteriormente, la construcción epistemológica de los derechos del hombre estuvo marcada por las antagónicas definiciones racionalistas, idealistas y religiosas que surgieron durante toda la historia del hombre, a la par con el surgimiento de la mencionada Declaración de los Derechos del Hombre. El pensamiento filosófico de la Europa de los siglos XVII, XVIII y XIX estaba enfocado en las opiniones críticas de I. Kant (1724-1804), para quien una máxima de vida moral (intención subjetiva) debía convertirse en una ley universal (realidad moral objetiva). Este imperativo categórico chocó con la idea hegeliana de una dialéctica más encarnecida, en donde los opuestos darían una síntesis que definiría cuál es la moral y el derecho del hombre en la sociedad. Para Hegel, la historia determina la razón y la libertad.

\section{La época de las declaraciones}

Alemania, diezmada por la derrota en la Primera Guerra Mundial y rematada por el“vergonzoso" "Pacto de Versalles", estaba preparada para que surgiera el caldo de cultivo de un exasperado nacionalismo. Para Antón (2013), el nacional-socialismo se nutrió de las ideologías de la seudo-sociología de Alfred Roseberg (1893-1946), en su obra Mythus des 20 Jahrhunderts. En él, propone la supremacía racial aria sobre las demás razas y la intromisión del pueblo judío en la historia de la humanidad; desde la aparición del mismo Jesucristo, quien para A. Rosemberg, es el fruto de la unión de una judía con un soldado romano originario de Germania. Tales afirmaciones -carentes de toda credibilidad demostrable, además de situaciones de tipo político, económico y social- fueron la base para el antisemitismo de este régimen, que se catapultó después con Adolf Hitler y su obra Mein Kampf (1925).

En España, el nacionalismo se estableció después de la Guerra Civil (1939). El General F. Franco (18921975) tomó su bandera, como adalid de los principios morales y religiosos del pueblo español; muy dife- 
rente a lo que sucedió en Alemania e Italia. En España, la religión católica jugó un papel muy importante en la construcción social de una España totalitaria: el Estado y la Iglesia eran la razón suprema, a la que todo individuo tenía que subordinarse.

Entre tanto, el capitalismo, como tal, se fue consolidando tras el triunfo de la Revolución Industrial. Y mantuvo su dialéctica racional-idealista: el poder del capital era -en sí- la supremacía sobre todo individuo. Este sistema de pensamiento y acción dominó las potencias no nacionalistas de comienzos del siglo XX: Reino Unido y Francia. Por su parte, Estados Unidos tomó la pauta del discurso capitalista para promover y expandir un criterio que, aunque no nuevo, venía muy recargado de esos términos del siglo XV: los del imperialismo.

Este panorama- tan discordante que cobijó al mundo, desde finales de la Primera Guerra Mundial- era un verdadero detonante que, en cualquier momento tenía que explotar. En ese momento, el concepto de derechos humanos tuvo una gran crisis de identidad: parecía que los derechos humanos estaban destinados a la consolidación de los intereses de esas fuerzas ideológicas y políticas, que se habían formado, para los nacionalistas y fascistas. Es decir que solo tenían derecho a la dignidad humana los conciudadanos de mi misma raza y de mi Estado; los demás debían ser conquistados y esclavizados, incluso, aniquilados.

Desafortunadamente, ese gran caldo de cultivo desencadenó la SGM. Durante este periodo, los extremismos de derecha e izquierda condimentaron masacres y genocidios humanos nunca antes vistos. Nunca antes, los DDHH habían estado tan amenazados, reducidos y vulnerados hasta el punto que la denominación de DDHH, prácticamente, desapareció.

Acontecimientos, como la SGM, dejaron unas profundas huellas en la geopolítica y el ordenamiento territorial del planeta. De hecho, en la actualidad, padecemos muchas de sus consecuencias: el conflicto árabe-Israelí, los continuos enfrentamientos en los Balcanes. También, varios de los avances: la ingeniería genética, la Declaración Universal de los DDHH, la ONU, la OTÁN; por citar solo algunos ejemplos que hunden sus raíces precisamente en las decisiones que tomaron las potencias "ganadoras" de dicho en- frentamiento; si es que se puede hablar de ganadores en una guerra.

En este orden de ideas, cabe preguntarse: ¿se puede hablar de DD-HH después de Auszchwitz?, ¿después de Iroshima y Nagasaki?, ¿después de los campos de exterminio de Birkenau, Belzec, Sobibor, Treblinka, Majdanek y Chelmno?, ¿después del Holocausto judío?, ¿después de la Primera y Segunda Guerra Mundial, cuyas víctimas ascendieron a más de 65 millones?, ¿después de las brutales guerras coloniales y las múltiples masacres étnicas?, ¿después del fracaso de la ideologías?, ¿después del comunismo con sus millones de víctimas y de su desplome asombroso hace apenas 20 años? Más aún: ¿se puede ser humanista después del gulag, la amenaza nuclear y los terrorismos?, ¿se puede ser humanista después de la guerra fría y de los atentados terroristas del $11 \mathrm{~S}$ en EEUU y el 11M en España?, ¿después de las políticas de sospecha y amenaza de guerras entre países hermanos de América Latina?, ¿después de la exclusión de los países llamados del eje del mal Iraq, Irán, Corea del Norte, Libia y Cuba?

Al finalizar la Segunda Guerra Mundial, el mundo quedó polarizado en dos frentes: el comunista y el capitalista. Ambos dominados por las potencias vencedoras, sobre todo, por la URSS y los Estados Unidos de América. Entonces, era menester hacer germinar la semilla que -por allá en Francia, en 1789- se había cultivado como Declaración de los Derechos del Hombre. Las potencias Aliadas, lideradas por Estados Unidos, se consolidaron estos derechos: a) que el genocidio de SGM no se repitiera, bajo ninguna circunstancia; b) que los autores de las atrocidades cometidas contra los derechos humanos fueran castigados; así, nacieron los llamados Juicios de Nüremberg.

Si bien el 1 de enero de 1942 las potencias aliadas se comprometieron a que, una vez se terminara la guerra iban a procurar una protección general de los DDHH, solo hasta 1946, se logró crear una Comisión de Derechos Humanos (como aparte del Consejo Económico y Social), compuesta por ocho integrantes. Se destacan, especialmente, Eleanor Roosvelt (presidenta) y Rene Cassin (vicepresidente).

Tras dos años de propuestas y modificaciones, el 10 de diciembre de 1948 se presentó el tex- 
to definitivo para su aprobación a la Asamblea General de las Naciones Unidas. La Unión Soviética y algunos países de su área de influencia (más Arabia Saudita y Sudáfrica) se abstuvieron durante la votación, y el texto fue aprobado por gran mayoría (48 votos a favor, 8 abstenciones y ningún voto en contra). (Amnistía Internacional, 2009, p. 72).

Dicha Declaración constituye, quizás; el hito más destacado en la consolidación de los $\mathrm{DDHH}$, tal como los conocemos en la actualidad. En efecto, son un referente internacional, cuyo articulado ha sido asumido de manera paulatina por la mayoría de democracias contemporáneas del siglo XXI. El documento final está compuesto por 30 artículos.

En este punto, vale la pena destacar el preámbulo de la Declaración que considera que los Derechos Fundamentales están enraizados en la dignidad y el valor de la persona humana, pues se trata de derechos inalienables que han de ser respetados por todos los Estados para que el hombre no se vea obligado, como recurso supremo, a rebelarse contra la tiranía y la opresión.

Considerando que la libertad, la justicia y la paz en el mundo tienen por base el reconocimiento de la dignidad intrínseca y de los derechos iguales e inalienables de todos los miembros de la familia humana... Considerando que los pueblos de las Naciones Unidas han reafirmado en la Carta su fe en los derechos fundamentales del hombre, en la dignidad y el valor de la persona humana y en la igualdad de derechos de hombres y mujeres. (Declaración Universal de los Derechos Humanos, Preámbulo).

Entre los derechos humanos que contiene su articulado, se consignan: la prohibición de la esclavitud (Art. 4), la tortura, penas inhumanas o degradantes (Art. 5), de las detenciones y exilios arbitrarios), de los efectos retroactivos de las leyes penales, de la privación de la nacionalidad, de la restricción de la libertad de movimientos, prohibición de la confiscación de bienes. También, están: la enunciación de las libertades de opinión, de expresión, de información, de conciencia y religión, de reunión y asociación pacíficas. (Declaración Universal de los Derechos Humanos, 1948).
El artículo 28 habla sobre el derecho a que reine un orden social e internacional, para que los derechos y libertades, contenidos en la Declaración, puedan encontrar plena efectividad. Hay que tener en cuenta que por tratarse de una Declaración, es carente de obligatoriedad jurídica para los Estados, es decir, no tiene fuerza de ley vinculante. Esta fuerza se adquiere en el momento en que cada Estado los articula a su propia constitución, a través de la cual se pueden estipular leyes de obligatoriedad de cada uno de los derechos; sobre todo, los fundamentales.

Se trata, entonces, de una carta de navegación internacional con fuerza moral, que su propio articulado le atribuye. Por ello, solamente es posible obtener la protección de aquellos derechos por los individuos, acudiendo ante los tribunales de su propio Estado, sin que tenga atribuida, en caso de violación o desconocimiento, acción ante un tribunal u organismo internacional específico.

Una vez terminada la SGM y con el esqueleto bien formado de los derechos humanos, se empezó una discusión sobre las características de los mismos. Así, surge un cúmulo de intentos para caracterizarlos.Y se determinaron, como innegociables, inviolables, indivisibles, obligatorios, irreversibles, progresivos, interdependientes, complementarios y otros más. Es más, a lo largo del tiempo, los DDHH se han identificado, principalmente, por contener tres características que los identifican: absolutos, inalienables y universales. En este sentido, varios autores, tales como Jesús González Amuchategui y Francisco Laporta, consideran:

Son tres características básicas de los Derechos Humanos: 1) son universales: se adscriben a todos los seres humanos, con independencia del sistema jurídico en el que vivan; 2) son absolutos: tienen una fuerza e importancia sobresaliente debido al estados de cosas que protegen; desplazan a otros requerimientos morales y solo entran en conflicto con otros derechos humanos. 3) son inalienables: sus titulares no pueden renunciar a ellos, tienen la obligación de respetarlos no solo en los demás, sino también en sí mismos. (Laporta, 1987, p. 32).

Pero ha sido la característica de universalidad, la que más problemas e inconvenientes ha presentado para los DDHH, tanto de orden cualitativo como de orden 
cuantitativo. Ha entrado en confrontación con culturas, ideas de dignidad y sistemas ético-morales, dado que cada país tiene su marco jurídico, al que acomoda, según diversos criterios y conveniencias. Esta característica fue el talón de Aquiles que ha marcado el devenir histórico de los DDHH.

En nombre del estatus jurídico de los DDHH, cada país, sobre todo las potencias, tomaron una definición propia sobre derechos humanos. Se ve, de esta manera, cómo la jurisprudencia termina encerrando los DDHH bajo una frontera difícil de salvar, porque -como reza el buen relativismo- todo depende del cristal con que se mire. Entonces, lo que para unos es defensa de la integridad y los derechos del hombre; para otros, es subversión, terrorismo o vulneración a la seguridad social y estatal. En este sentido, cada sistema democrático creó su propia cátedra sobre DDHH, a lo largo de la segunda mitad del siglo $X X$. Esto desembocó en las nuevas luchas y guerras para implantar modos de pensar a las minorías $\mathrm{y}$, así, comenzar a vulnerar sus más elementales derechos. África y América han sido testigos de este panorama, en las décadas de la posguerra. Todo, con un frío balance: la incertidumbre de una consolidación universal de los Derechos del Hombre.

Lo anterior ha dado origen a las brutales guerras coloniales y a las múltiples masacres étnicas, por ejemplo el GULAG y el Apartheid, las amenazas nucleares y los terrorismos, la guerra fría y los atentados terroristas del 11S en EEUU y el 11M en España; las políticas de sospecha y amenaza de guerras entre países hermanos de América Latina, la exclusión de los países llamados del eje del mal Iraq, Irán, Corea del Norte, Libia y Cuba, etc.

Los derechos humanos, como concepto fundamental, se vieron vulnerados durante el periodo de las dictaduras en América Latina. Sobre todo, en el cono sur (Argentina, Uruguay, Chile), en donde, desde 1968, las diferentes dictaduras militares de derecha prácticamente aniquilaron cualquier vestigio de oposición o de libre pensamiento. El actuar de estos regímenes siempre estuvo respaldado -aunque muy discretamente- por la política de Estado norteamericana, que veía, en cualquier manifestación de simpatía izquierdista, un verdadero peligro para la estabilidad capitalista de Estados Unidos y sus países satélites.
Según Chernick (1998), la moda de los "procesos de paz" se impuso en el escenario de fin de siglo. Así se hizo en Colombia con el M-19 y en El Salvador y en Nicaragua con las mesas de negociación. Dichos procesos se perfilaron como los nuevos estandartes de la reivindicación de los derechos humanos. Al mismo tiempo, el narcotráfico se posicionaba como nuevo manager de los conflictos; sobre todo en Colombia.

La década de los ochenta significó para Colombia, el apocalipsis de la violencia representada por el poder del narcotráfico, frente a la debilidad del Estado. En este caso, el Estado se subordinó al poder de los carteles y los derechos humanos nuevamente sufrieron la más cruenta realidad.

El caso colombiano es un claro ejemplo de cómo un discurso, como el de los derechos humanos, bajo condiciones de conflicto y violencia, genera una gran dificultad para ser llevado a la práctica. Se encuentra, entonces, que tanto el discurso como la realidad carecen de una misma orientación y que aspectos como los derechos humanos no deben ser estudiados y exigidos de la misma forma que se hace en otros contextos y sociedades, donde la violencia y la desigualdad no son algunos de los factores que los caracterizan. (Nieto, 2004, p. 15).

Las minorías -las mujeres, los niños, los ancianoshan sido tema de debate, en cuanto se refiere a los derechos humanos. El largo proceso, mediante el cual la mujer ha logrado reivindicaciones visibles en la sociedad, no ha sido fácil. La violación, el maltrato físico y psicológico, el aborto, la prostitución, la trata de blancas son la baraja que, en cuanto a derechos humanos, ha exigido la mujer. Realmente, el camino hacia la total salvedad de estos temas está todavía en un tránsito medio. Todo depende de la voluntad de los Estados y las organizaciones sociales; por encima de doctrinas, creencias y viejas premisas.

Los derechos humanos no son una ciencia exacta, no es un racionalismo puro. Son un constante debate que nos hace reflexionar sobre la importancia de la diversidad de género, etnia, sexual, creencias, formas de vida, costumbres, ideales, ideologías, culturas, folclor, patria, familia y sociedad. 


\section{Conclusiones}

Los derechos humanos se configuraron, desde los tiempos antiguos, como una síntesis de la realidad moral y ética de los hombres. Pretenden desentrañar los aspectos más importantes de la realidad del comportamiento del hombre, con la sociedad que lo cobija.

Suárez (2005) sintetiza, de manera magistral, que, en la historia de la formación de los DDHH, se pueden distinguir, por lo menos tres momentos bien determinados:

- El primero se puede buscar en las obras de los filósofos y teorías ético-políticas. Cuando estas teorías son aceptadas, en la Declaración de los Derechos de los Estados Americanos y de la Revolución Francesa, y sirven de base para una nueva concepción del Estado.

- El segundo es el paso de la teoría a la práctica. Se gana en concreción, pero se pierde en universalidad. Valen solo en el ámbito del Estado que los reconoce a partir de la Carta Magna de cada país.

- El tercero lo constituye la Declaración del 48 que da comienzo a un nuevo devenir histórico de los DDHH, como una declaración universal y positiva. Universal, porque no solo son destinatarios los ciudadanos de aquel Estado, sino todos los hombres.Y positiva, porque pone en movimiento un proceso de positivización universal, a través de medidas eficaces para garantizar la existencia de una comunidad internacional, incluso, de una ética universal basada en la fuerza moral de los DDHH.

El libro Ensayo sobre la ceguera de José Saramago, parece ser una reflexión sobre la condición humana, en general. Sobre todo, el comportamiento que los humanos tenemos en condiciones extremas de crisis. Saramago (1995) relata la aparición de una extraña enfermedad, una especie de ceguera desconocida, que surge sin ningún malestar previo y que se contagia inmediatamente, con solo permanecer cerca de aquel que sufre el mal. A partir de esta idea, el autor construye un relato lleno de reflexiones acerca de la conducta de los hombres frente a esta epidemia.

Esta analogía llevar a interpretar los derechos humanos como la vacuna y el remedio para la ceguera del hombre frente a sus realidades y su comportamiento. De ahí que los DDHH sean un instrumento dialógico-dialéctico para construir nuevos discursos, nueva prácticas; sobre todo nuevas (inter) relaciones con unos mínimos de civilidad y de respeto, hacia nuestros semejantes primeramente. Pero, también, hacia los otros seres de la creación.

\section{Referencias}

Álvarez -Gómez, J. (1955). Historia de la Iglesia Católica. Edad Antigua. Tom I. Sapienta Fidei. Serie de manuales de teología. Biblioteca de autores cristianos (Eds.)Madrid, España. 384p.

Alzamora- Valdez, M. (1963). Introducción a la Ciencia del Derecho. Talleres Gráficos P. L. Villanueva S. A. Lima, Perú. 335 p.

Amnistía Internacional. (2009). Historia de los Derechos Humanos. Grup d'Educació, Amnistia Internacional Catalunya (Eds.). 105 p.http:// www.amnistiacatalunya.org/edu/pdf/historial dudh-historia.pdf.

Antón, J. (2013). Análisis, El pedante filósofo del nazismo Alfred Rosenberg. Insufriblemente arrogante y pedante. El día a día de la barbarie nazi. Barcelona, España. http:// cultura.elpais.com/cultura/2013/06/10/actualidad/1370891924_378025.html.

Aranguren, J. L. (2001). Ética. 9a Ed. Revista de Occidente- Madrid, España. http://plesiologos.blogspot.com/2008/11/moral-como-estructura-y-la-moral-como.html.

Bobbio, N. \& Bovero, M. (1996). Sociedad y estado en la filosofía moderna. El modelo iusnaturalista y el modelo Hegeliano-Marxiano. Fondo de Cultura Económica (Eds.). México. 272 p.

Borón, A. (2000). La filosofía política moderna. De Hobbes a Marx. Consejo Latinoamericano de Ciencias Sociales - CLACSO (Eds.). Buenos Aires, Argentina. 448p.

Chernick, M. (1998). Las dimensiones internacionales de los Conflictos Internos en América Latina: de la guerra fría (a la paz negociada en Centroamérica) a la guerra antinarcótica. Colomb Int, 41, 5-43. http://colombiainternacional. uniandes.edu.co/view.php/324/index.php?id=324

Hume, D. (2014). Investigación sobre los principios de la moral. Alianza Editorial. Madrid, España. 241p.http://juliobeltran.wdfiles.com/ 
localfiles/cursos:ebooks/Hume,\%20D._Investigaci\%C3\%B3n\%20sobre\%20los\%20principios\%20de\%20la\%20moral.pdf

Londoño-Toro, B. (2002). Organizaciones no Gubernamentales y Derechos Humanos. Retos para construir una sociedad civil en Colombia. Credencial Historia, 156. http://www.banrepcultural. org/blaavirtual/revistas/credencial/diciembre2002/ organizaciones.htm.

Laporta-San Miguel, F.J. (1987). Sobre el concepto de derechos humanos. Doxa, 4, https://doi.org/ 10.14198/DOXA1987.4.01

Lara-Peinado, F. (1982). Código de Hammurabi. Editora Nacional (Eds.).Madrid, España. 229p.

Marina, J.A. (2007). ¿Aún son diez los mandamientos? http://www.dios.com.ar/notas1/enigmas/conjeturas/mandamientos/mandamientos.htm

Meeter, H. (s.f.). La Iglesia y el Estado. 3a ed. The Evangelical Literature League (TELL) (Eds.).USA.

Montesquieu, R. \& Durkheim, E. (1960). Forerunners of sociology. Ann Arbor: The University of Michigan Press (Eds.). USA. 155p.

Moreno- Giraldo, J. (2010). Derechos humanos y cristianismo trasfondos de un conflicto. El Búho Ltda (Eds.). Bogotá, Colombia. 127p.

Nieto, R. (2004). Derechos humanos en Colombia. Verdades y mentiras. Colección Revelaciones. Bogotá, Colombia. 127p. http://unoamerica.org/ unoTest/upload/apps/verdadesespanol.pdf.

ONU. (1948). Declaración universal de los derechos humanos. París, Francia. http://www.ohchr.org/ EN/UDHR/Documents/UDHR_Translations/spn. $p d f$

ONU (1989). Convención sobre los derechos del niño. http://www.margen.org/ninos/derech8b.htm

Papacchini, Á. (1945). Filosofía y derechos humanos, fueron creados y ratificados en el año 1945 de la pág. 44; de forma similar, Nino, Carlos S. Ética y derechos humanos, pág. 40. El concepto“bienes primarios" procede de John Rawls.

Papacchini, Angelo (1998). Los Derechos Humanos a través de la Historia. Revista Colombiana de Psicología, 7, 138-200. http://www.revistas.unal.edu. co/index.php/psicologia/article/view/16061/16942

Peces-Barba, G. (1991). Curso de derechos fundamentales. Teoría General. Universidad Carlos III. Eudema (Eds.). Madrid, España. 720p.

Ramírez-Echeverri, J.D. (2010). Thomas Hobbes y el Estado absoluto: del Estado de razón al Estado de terror. Facultad de Derecho y Ciencias Políticas, Universidad de Antioquia, Medellín. Colección mejores trabajos de grado. 107p. http:// www.udea.edu.co/wps/wcm/connect/udea/55e0d52c-27ba-4e16-95d2-2aa13d932777/Hobbes+del+Estado+de+razon+al+Estado+de+terror.pdf?$M O D=A J P E R E S$

Saramago, J. (1995). Ensayo sobre la ceguera. Camino (Eds.). México. 244p. http://www.fts.uner.edu.ar/ discapacidad/discap_2008/articulos/jose\%20saramago_ensayo\%20sobre\%20la\%20ceguera.pdf.

Suárez, J.M. (2005). Presente y Futuro de los Derechos Humanos. Lorena González Volio (Eds.). 431 p.http://www.monografias.com/trabajos28/ presente-futuro-derechos-humanos/presente-futuro-derechos-humanos.shtml

Vitoria, F. (1975). Relecciones sobre los indios y el derecho de guerra. Espasa-Calpe (Eds.), 3a ed. Colección Austral. Madrid, España. 172p. http://www.uv.es/correa/troncal/resources/Relectio-prior-de-indis-recenter-inventis-Vitoria.pdf

Voltaire (2006). Tratado sobre la tolerancia. S.L.U. Espasa Libros (Eds.). Barcelona, España. 280p. 